
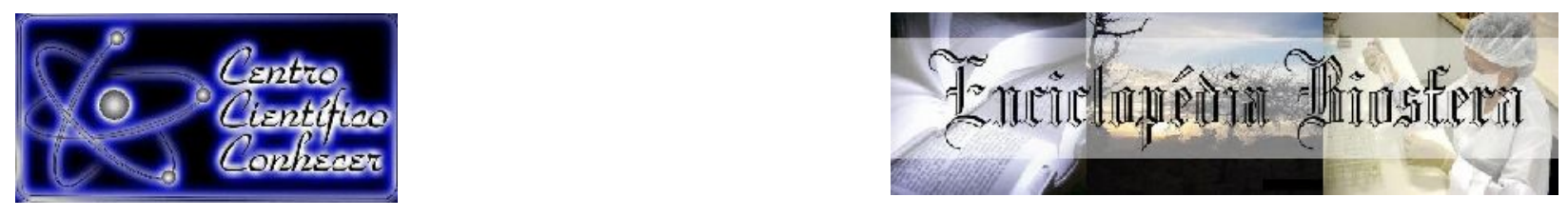

\title{
CARACTERIZAÇÃO DO PERFIL DE INDIVÍDUOS QUE RESGATAM ANIMAIS EM SITUAÇÃO DE MAUS TRATOS
}

Viviane Aguiar de Souza ${ }^{1}$, Ana Paula Iglesias Santin ${ }^{2}$

${ }^{1}$ Acadêmica em Medicina Veterinária, da Escola de Veterinária e Zootecnia da Universidade Federal de Goiás (EVZ/UFG), Goiânia, Brasil

(viviane_aguiar_souza@hotmail.com)

${ }^{2}$ Professor Associado da EVZ/UFG, Goiânia, Brasil (apisantin@gmail.com)

Recebido em: 06/04/2019 - Aprovado em: 10/06/2019 - Publicado em: 30/06/2019

DOI: 10.18677/EnciBio_2019A36

\begin{abstract}
RESUMO
A superpopulação de cães e gatos errantes nos centros urbanos aumenta consideravelmente a cada dia. Em contraste, não há políticas públicas voltadas ao controle e resolução desse problema. Diante disso, alguns cidadãos voluntariamente resgatam animais desamparados que estão abandonados e passíveis de maus tratos nas ruas. Por isso, são conhecidos como protetores independentes, os quais resgatam, acolhem e cuidam devidamente até que o animal esteja apto a ser disponibilizado à adoção. Este trabalho teve como objetivo caracterizar o perfil desses indivíduos. Cinquenta questionários foram respondidos com informações acerca de características pessoais e experiência na proteção animal. Observando-se maior incidência de pessoas do sexo feminino, solteiras, com ensino fundamental incompleto, sem filhos, enfrentam dificuldade para encontrarem lares temporários e utilizam de renda própria para manutenção dos animais resgatados. Estas informações permitem verificar a importância destes protetores na causa animal.
\end{abstract}

PALAVRAS CHAVE: Abandono, proteção animal, protetor independente, resgate.

\section{PROFILE CHARACTERIZATION OF PEOPLE WHO RESCUE MISTREATMENT ANIMALS}

\begin{abstract}
Dog and cat overpopulation in urban centers are growing up wildly. Instead there are no public policies aimed at controlling and solving this problem. In response, some volunteers rescue abandoned animals. These volunteers are called independent protectors. They have responsibility of animal care until adoption. The aim of this study was to characterize protectors profile. Fifty questionnaires were completed with personal characteristics and their animal protection experience. There was a higher incidence of women, single people, incomplete primary education, no children and it is difficult to find temporary homes. They also use their own money for the maintenance of rescued animals. This information makes it possible to verify the importance of the protectors in the animal cause.
\end{abstract}

KEYWORDS: Abandonment, animal protection, independent protector, rescue, 


\section{INTRODUÇÃO}

De acordo com a Organização Mundial da Saúde, há cerca de 30 milhões de animais abandonados no Brasil, este é um problema frequente não só no Brasil, mas em toda América Latina. A presença destes animais em locais públicos ocasiona diversas consequências, uma vez que não há nenhum tipo de supervisão, restrição e cuidados veterinários. Entre os diversos fatores que propiciam este problema, pode-se citar o baixo nível educacional juntamente com falta de consciência sanitária, e a ausência de comprometimento, por parte do poder público, que levam a um crescente aumento do número de cães em situação de rua, resultando em crias indesejadas e uma superpopulação (MOUTINHO et al., 2017; OMS, 2018).

$\mathrm{Na}$ sociedade atual, existem pessoas que por conta própria se voluntariam a resgatar, cuidar de animais abandonados e encaminhá-los para adoção, são os protetores independentes. Os quais trabalham, estudam, possuem família, filhos e que às vezes acabam alterando sua rotina e estilo de vida pela causa animal (LEWGOY et al., 2015).

Contudo, os protetores lidam com uma carga psicológica pesada, resgatando ninhadas abandonadas em caixas de papelão, ou animais atropelados agonizando e até recebendo mensagens absurdas dizendo que o animal da família precisa ser encaminhado para algum abrigo ou ONG porque a pessoa vai se mudar, ou tem alergia, ou porque a mulher está grávida, a mãe não quer mais, etc. Tudo com o intuito de abandonar o animal. Além disso, também lidam com devoluções de adoções concluídas, por motivos ínfimos, mesmo com todo o esforço para serem mais criteriosos possíveis nas entrevistas e triagens de adoção (OSÓRIO, 2017a).

Este trabalho teve como objetivo caracterizar o perfil de indivíduos que tem em sua realidade e rotina o trabalho voluntário de resgatar, acolher, possibilitar o tratamento, castração e disponibilizar para adoção responsável, animais em situação de maus tratos, considerando inclusive o abandono. Dessa forma, será possível entender melhor os aspectos pessoais e socioeconômicos das pessoas envolvidas nesta causa. Essas informações projetam uma visão geral sobre os protetores independentes e podem embasar novas pesquisas a fim de evidenciar a função social que esses cidadãos desenvolvem e promover visibilidade à causa animal.

\section{MATERIAL E MÉTODOS}

Este trabalho foi desenvolvido através do preenchimento de um questionário (anexos) por pesquisadores do grupo, que obtiveram dados de protetores independentes ou ligados a grupos de proteção/ONG, que resgatam animais nas ruas em situação de abandono e/ou maus tratos. Este estudo foi realizado no período de agosto de 2017 a julho de 2018 e somou cinquenta questionários respondidos abrangendo Goiânia e região metropolitana.

Para facilitar o tratamento dos dados, as respostas foram organizadas sob a forma de alternativas. As questões foram inicialmente relacionadas com informações pessoais do participante como nome, profissão, tipo de moradia, e-mail, nível de escolaridade, sexo, faixa etária, estado civil, quantidade de filhos, renda média domiciliar, esta última baseada de acordo com a Associação Brasileira de Empresas de Pesquisa (ABEP, 2018). Posteriormente, as perguntas foram sobre a rotina/experiência da atuação como protetor de animais, especificando tempo de atuação, quantidade de animais resgatados e motivação para se responsabilizar por um animal abandonado; espécie, porte e características mais frequentes de animais resgatados; local onde o animal fica abrigado durante o processo até a adoção e 
variação de tempo que dura esse processo; parte do processo que demanda mais recurso financeiro e a origem desses recursos; quantidade de tempo diário e tempo livre direcionado a essa atividade; tipo e regularidade de hobbie/lazer; fatores limitantes da atuação; descrição da atitude das pessoas que sabem sobre essa atuação.

Após a coleta dos dados, os mesmos foram analisados e tabulados em planilha Excel e ferramenta Google Forms. O estudo estatístico para avaliação dos dados obtidos foi realizado por meio do Teste Qui-quadrado com proporções esperadas iguais dos resultados (Teste Qui-quadrado de aderência), utilizando-se o programa "Bioestat" 5.3. Foram consideradas, neste trabalho, diferenças significativas quando "p" apresentou valores inferiores a 0,05.

\section{RESULTADOS E DISCUSSÃO}

Apesar do grande número de pessoas envolvidas no resgaste de cães e gatos em situação de rua ou que são submetidos a maus tratos, não foi uma tarefa fácil conseguir os 50 participantes, como proposto na metodologia deste estudo, as pessoas não respondiam ou demoravam a responder os questionários, e às vezes já se mostravam indisponíveis ao primeiro contato.

Neste estudo, dos cinquenta questionários aplicados para caracterizar o perfil de indivíduos que resgatam animais nas ruas (abandonados) ou em situação de maus tratos, verificou-se alta diversidade profissional (Figura 1). Visto que foram identificadas trinta e seis diferentes ocupações, no que se refere a profissão dos protetores, presume-se a pluralidade de personalidades que dedicam tempo e despendem recursos financeiros na proteção animal, no entanto, este parâmetro não foi um fator determinante para o perfil do indivíduo envolvido na causa animal, característica também observada por Santos (2015).

Em relação ao tipo de moradia, foi verificado que $33(66 \%)$ participantes residiam em casa e 17 (34\%) moravam em apartamento. A partir desses dados, averiguou-se que houve um número significativamente maior de indivíduos que residiam em casas em relação ao que residiam em apartamentos $(p=0,0339)$.

A maioria dos envolvidos com resgate de animais mora em casa, esta característica facilita a ação, uma vez que também foi verificado que a maior dificuldade enfrentada pelas pessoas que resgatam animais é encontrar um local para o cão ou gato ficar até a sua adoção. Santos (2015), também menciona a dificuldade dos tutores devido às reclamações de vizinhos em função dos latidos simultâneos dos diversos cães, e, além disso, relata que as pessoas que acolhem esses animais normalmente utilizam recursos próprios e que há necessidade de se destinar muitos cuidados a estes animais, fatos semelhantes foram descritos neste estudo.

Já a manutenção de animais em condomínio, pela legislação vigente, só poderia ser vedada ou restringida, em caso de comprovação de importunação ao sossego, à salubridade ou à segurança (BRASIL, 1998). Nesse sentido, supõe-se que a boa convivência no direito de vizinhança exige de cada um, a observância de certas regras limitativas ao exercício do direito de propriedade e em condomínios prediais a posse de vários animais se torna inviável por limitação de espaço livre e possíveis incômodos à vizinhança. 


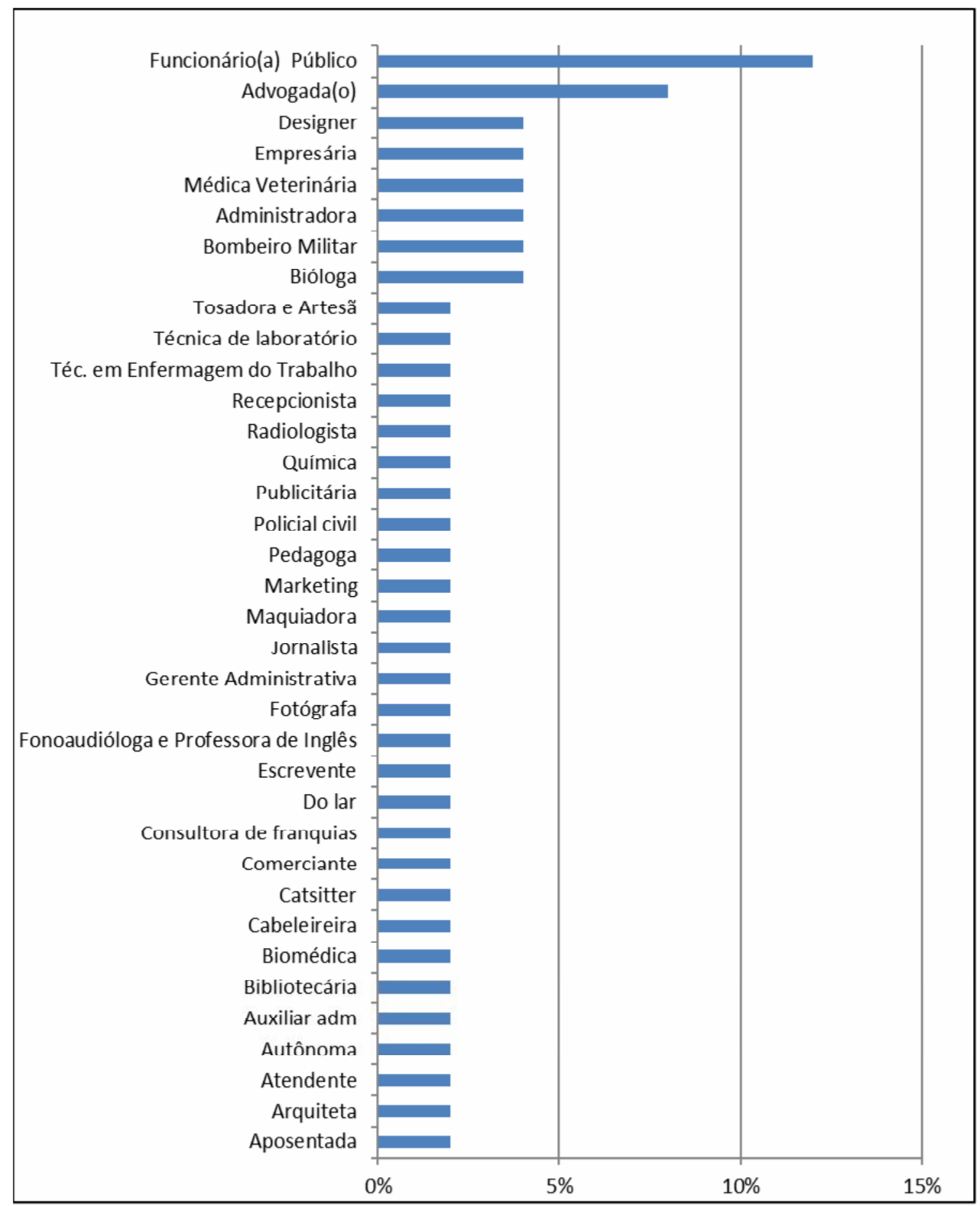

FIGURA1- Gráfico indicando a frequência das diferentes profissões, dos 50 indivíduos envolvidos no resgaste de animais abandonados ou submetidos a maus tratos, que participaram de estudo desenvolvidos nos anos 2017 e 2018, por meio de questionários.

Considerando-se o local onde o animal resgatado era abrigado até ser adotado, foi verificado que 32 participantes abrigam os animais em suas próprias residências, seja casa ou apartamento; 11 costumam abrigá-los na casa de amigos ou parentes que aceitam recebê-lo por um tempo; 24 acomodam os resgatados em lar temporário disponibilizado por alguém que também simpatiza com a causa e 20 
encaminham para algum local alugado, como clínica veterinária, abrigo que aluga baia, hospedagem.

A dificuldade de arrumar um local para o animal resgatado ficar até ser adotado (43 participantes) foi o principal fator limitante ou impasse com o qual as pessoas que resgatam animais têm que lidar, este foi seguido pela falta de recurso financeiro (39), a ausência de apoio do poder público (36) e o grande número de animais mantidos sob a responsabilidade da pessoa que oferece lar temporário aos cães e gatos resgatados (Tabela 1).

TABELA 1: Frequência e porcentagem dos fatores limitantes para o resgaste de novos animais, citadas por 50 indivíduos envolvidos com resgate de animais em situação de rua e por maus tratos, em estudo realizados nos anos de 2017 e 2018.

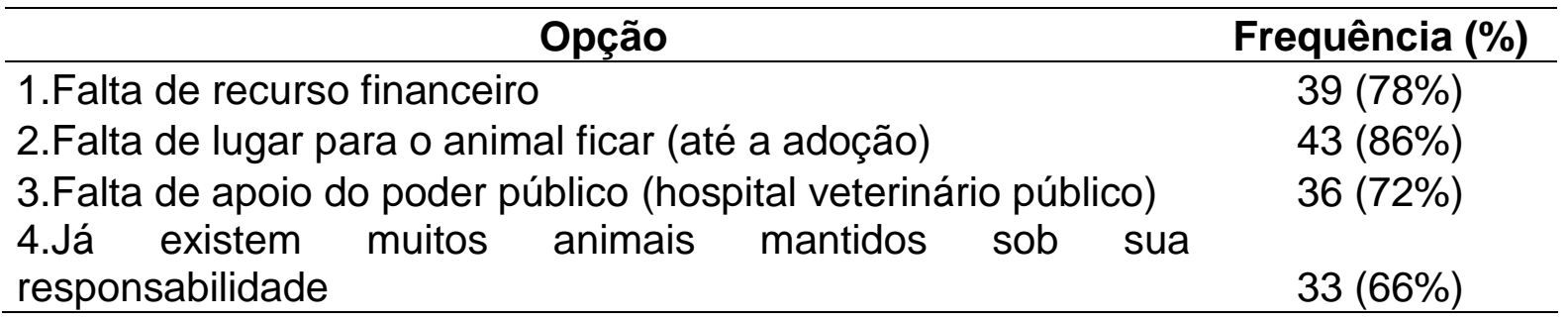

Entre os indivíduos que fizeram parte deste estudo, 22 (40\%) possuíam curso superior completo, 18 (36\%) já eram pós-graduados, cinco (10\%) tinham ensino médio completo, três $(6 \%)$ curso superior incompleto, um $(2 \%)$ participante ensino médio incompleto e um (2\%) ensino fundamental incompleto (Figura 2). A partir desses dados averiguou-se que houve um número significativamente maior $(p=0,0001)$ de pessoas com curso superior completo e pós-graduação, envolvidas no resgate de animais, quando comparados aos demais níveis de escolaridade.

O nível educacional também parece influenciar na adesão à causa animal, verificou-se uma grande quantidade de indivíduos graduados e pósgraduados se dedicando ao resgate de animais. Molento et al. (2005), que trabalharam com posse responsável, notaram uma associação entre posse responsável, com maior poder aquisitivo e nível educacional mais elevado, que auxiliaram também no processo de tomada de decisão quanto ao controle reprodutivo de cães e gatos em vilas rurais do Paraná. Nascimento e Paixão (2015) também descreveram sobre a escolaridade dos gestores de Organizações Não Governamentais (ONGs) de proteção animal e observaram que 78,6\% tinham formação superior e, destes, $18,2 \%$ eram pós-graduados em nível de especialização e $9,1 \%$ em nível de mestrado. 


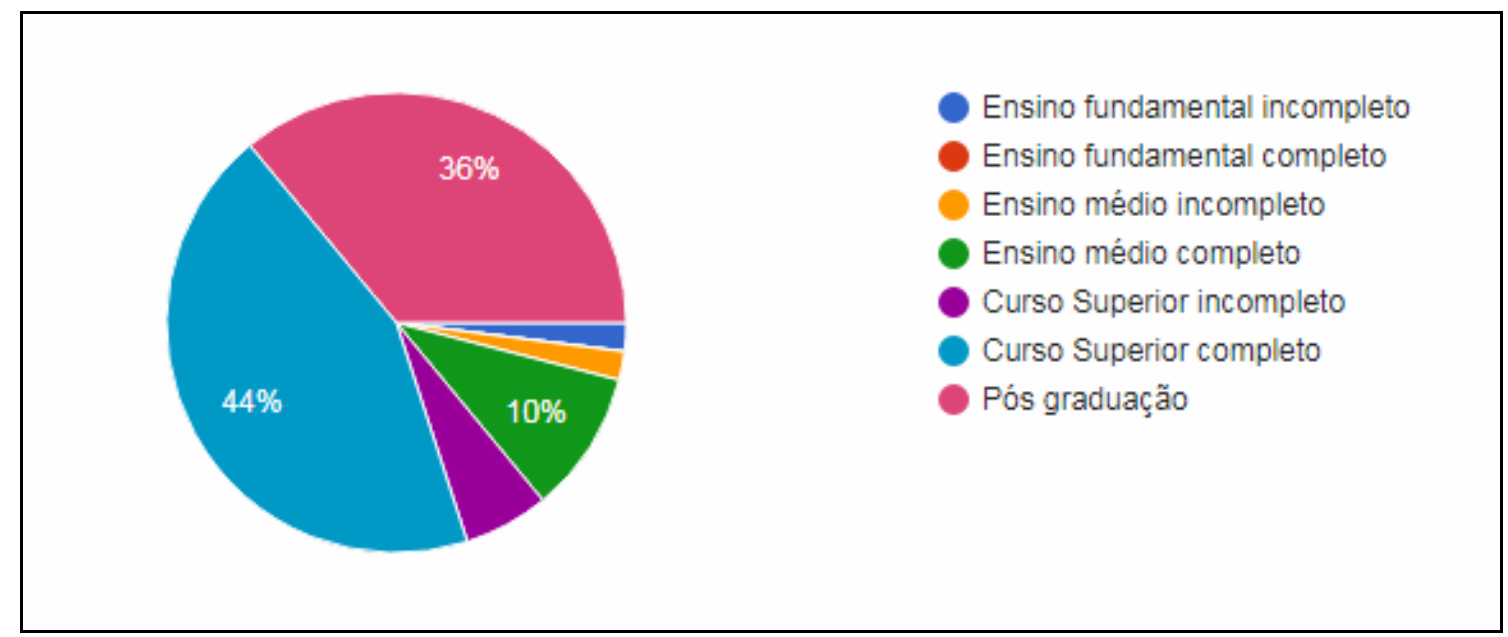

FIGURA 2- Gráfico indicando a frequência, de acordo com o grau de escolaridade, de 50 indivíduos envolvidos no resgaste de animais abandonados ou submetidos a maus tratos, que participaram de estudo desenvolvido nos anos 2017 e 2018, por meio de questionários.

Em relação ao sexo, notou-se um número significativamente maior de indivíduos do sexo feminino, correspondendo à $46(96 \%)$ indivíduos, participando do resgaste de animais, comparado à $4(8 \%)$ pessoas do sexo masculino, com $\mathrm{p}=$ 0,0001 (Figura 3). O maior número de mulheres envolvidas neste tipo de ação, demonstra efetivamente que a presença feminina tem sido ativa e prevalente na causa animal, fato também observado por Morais et al. (2014) e Osório (2017b). Revelando, desse modo, que as mulheres se mostram mais sensíveis pelos que não tem voz e pelos indefesos, e lutam pelos direitos de um coletivo oprimido, como os animais.

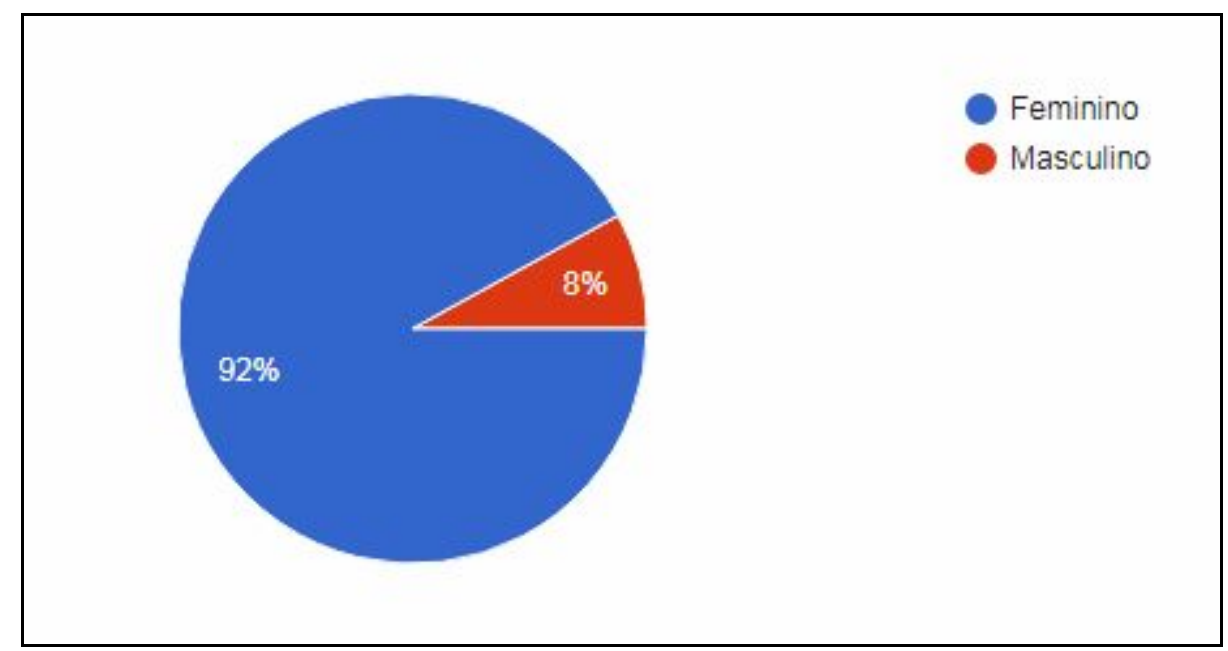

FIGURA 3- Gráfico indicando a frequência, de acordo com 0 gênero sexual, de 50 indivíduos envolvidos no resgaste de animais abandonados ou submetidos a maus tratos, que participaram de estudo desenvolvidos nos anos 2017 e 2018, por meio de questionários. 
Em relação à faixa etária, verificou-se que 18 participantes $(36 \%)$ tinham mais de 40 anos, $16(32 \%)$ tinham entre 25 a 30 anos, $15(30 \%)$ tinham entre 30 a 40 anos e apenas 1 (2\%) tinha entre 18 a 25 anos (Figura 4). A partir desses dados, averiguou-se que o número de indivíduos entre 18 a 25 anos foi significativamente menor quando comparado ao de pessoas maiores de 25 anos $(p=0,0023)$.

Praticamente, não foi observada a atuação de protetores na faixa etária entre 18 a 25 anos. Paralelamente, dados divulgados, em setembro de 2017, pelo Instituto de Pesquisa Econômica Aplicada (Ipea), evidenciou alto índice de desemprego dos jovens, em que $57 \%$ estão desempregados há mais de um ano (IBGE, 2018). Como pôde ser verificado o fator econômico é um elemento importante, quando se refere ao resgate de animais, uma vez que cães dão despesas, é fundamental ter consciência do custo para se manter um, até mesmo para planejar os gastos e proporcionar ao bichinho qualidade de vida (SANTOS, 2015). Em relação à demanda financeira, quase a totalidade dos protetores indicaram que os cuidados veterinários como consultas e exames é a parte mais onerosa.

Por outro lado, acredita-se que as pessoas com mais de 40 anos, normalmente apresentem maior estabilidade financeira, e também mais tempo disponível para se dedicarem à causa, resultado semelhante foi observado por Morais et al. (2014).

Dos participantes deste estudo, 20 (40\%) eram casados e os outros 30 $(60 \%)$ eram solteiros ou divorciados (Figura 5). Apesar do número maior de indivíduos solteiros ou divorciados não foi observada diferença significativa quando comparado ao grupo de pessoas casadas $(p=0,2031)$.

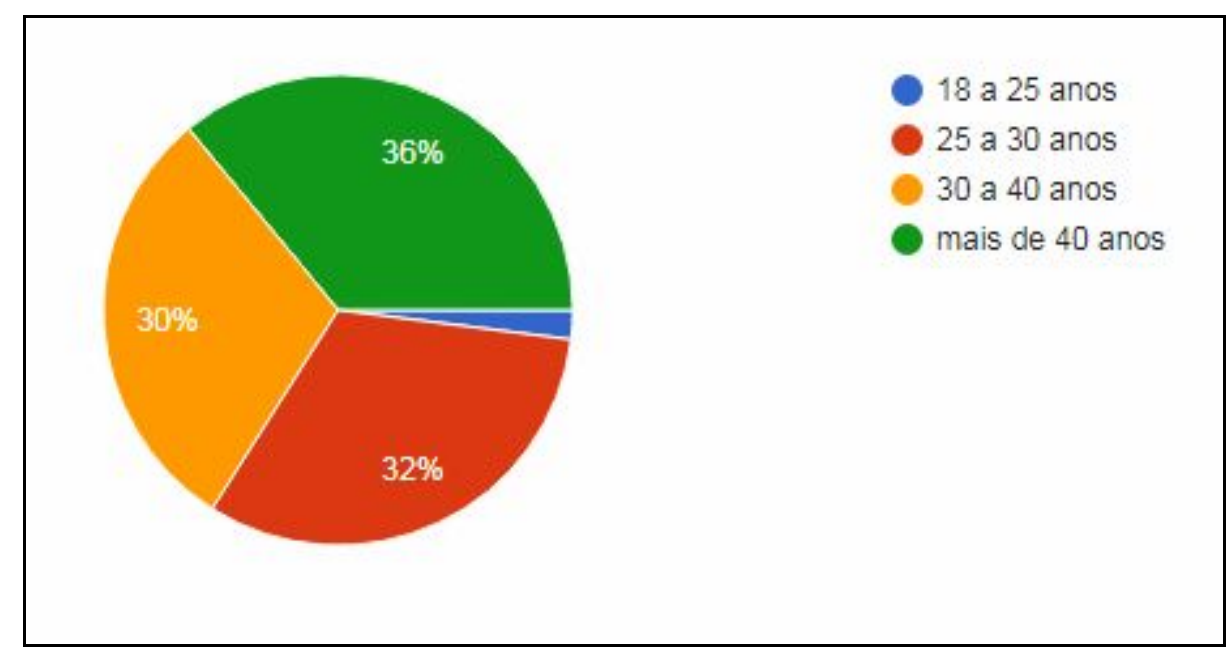

FIGURA 4- Gráfico indicando a frequência, de acordo com a faixa etária, de 50 indivíduos envolvidos no resgaste de animais abandonados ou submetidos a maus tratos, que participaram de estudo desenvolvido nos anos 2017 e 2018, por meio de questionários. 


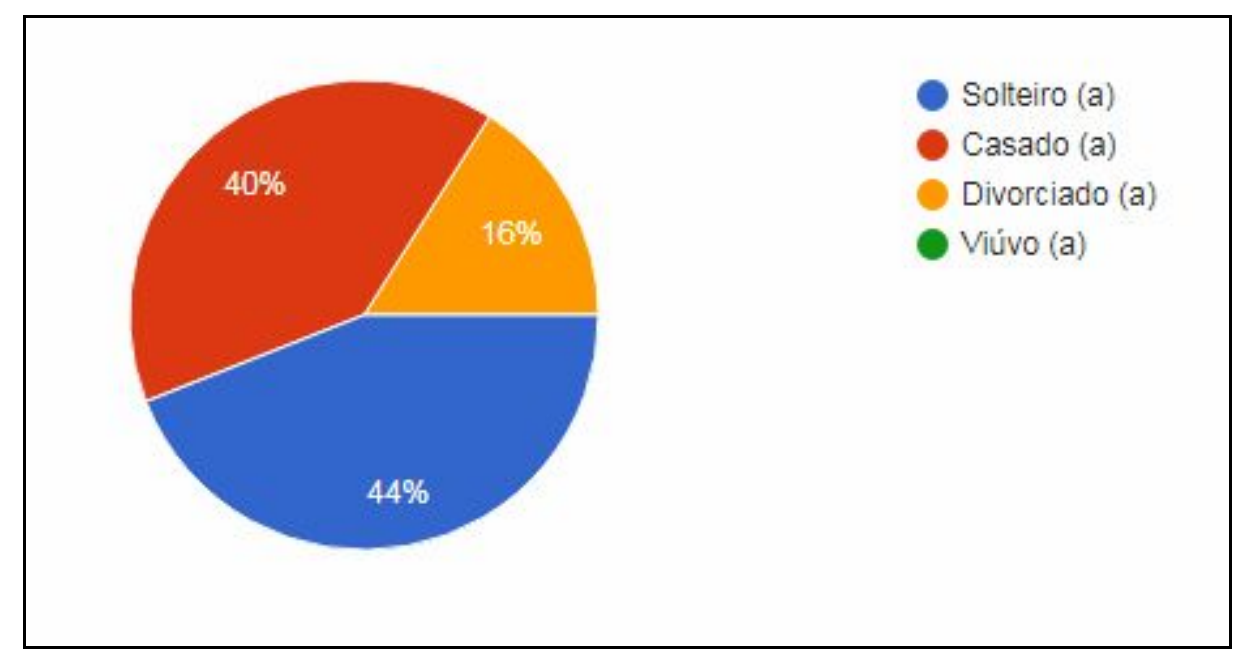

FIGURA 5- Gráfico indicando a frequência, de acordo com o estado civil, de 50 indivíduos envolvidos no resgaste de animais abandonados ou submetidos a maus tratos, que participaram de estudo desenvolvido nos anos 2017 e 2018, por meio de questionários.

Em relação à quantidade de filhos, foi verificado que 36 indivíduos (72\%) não possuíam nenhum filho, oito (16\%) possuíam um filho e seis (12\%) possuíam dois filhos (Figura 6). Portanto, há um número significativamente maior de indivíduos sem filhos envolvidos no resgaste de animais em situação de rua ou maus tratos $(p=0,0001)$.

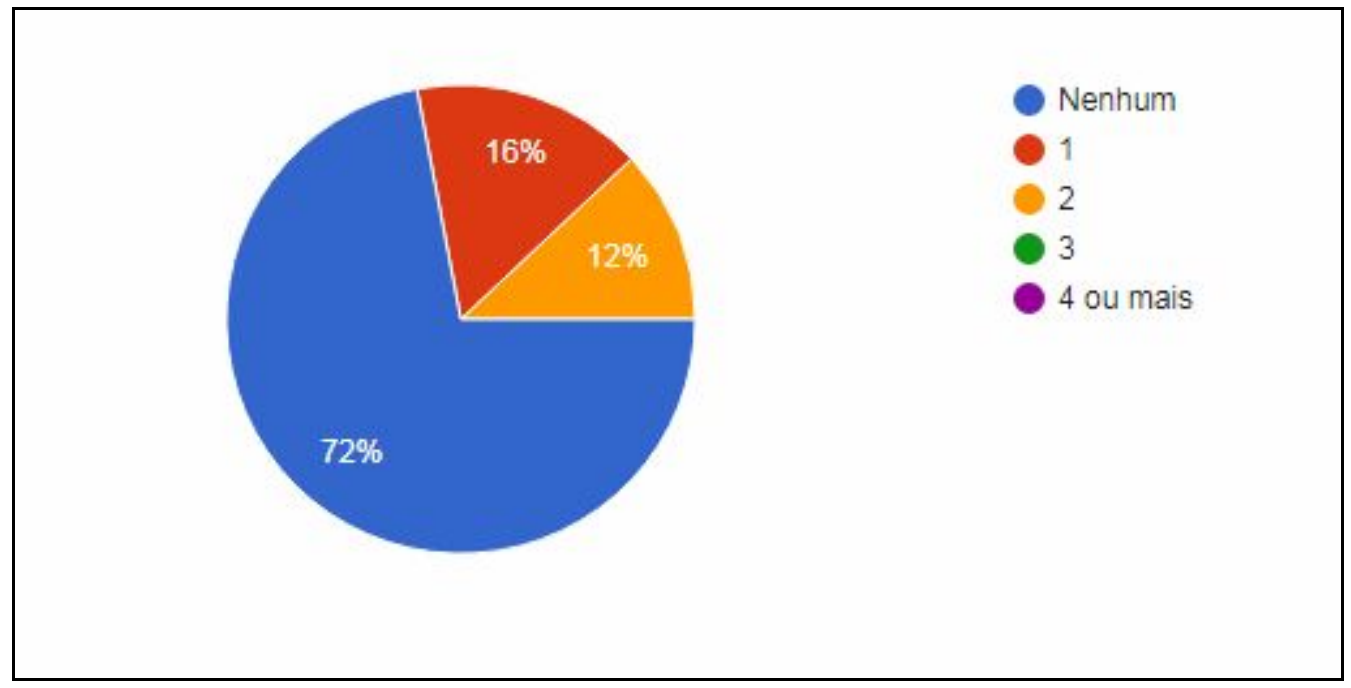

FIGURA 6- Gráfico indicando a frequência, de acordo com a quantidade de filhos, de 50 indivíduos envolvidos no resgaste de animais abandonados ou submetidos a maus tratos, que participaram de estudo desenvolvido nos anos 2017 e 2018, por meio de questionários. 
Em relação à renda média domiciliar, foi verificado que 21 participantes (42\%) recebiam de dois a cinco salários mínimos, 17 (34\%) de seis a 10 salários mínimos, nove (18\%) mais de 10 salários mínimos e apenas três $(6 \%)$ até um salário mínimo (Figura 7). A partir desses dados, averiguou-se que houve diferença significativa em relação à renda média domiciliar dos participantes $(p=0,0014)$, e que esta foi dada devido ao número significativamente menor de participantes que possuem renda média domiciliar de até um salário mínimo.

Em relação à renda média domiciliar, baseando a renda média domiciliar pelo critério de classificação econômica Brasil da $A B E P$, foi estabelecido que os estratos socioeconômicos C $(R \$ 1.691,44$ a $R \$ 5.363,18)$ e $B(R \$ 5.363,19$ a $R \$$ $23.345,10$ ) foram os predominantes, entre os indivíduos que resgatam animais em situação de rua ou maus tratos. Este resultado vai de encontro com os elevados gastos que estes têm com os animais, sendo que a maioria utiliza renda própria para manter os animais acolhidos, relato semelhante foi feito por Morais et al. (2014).

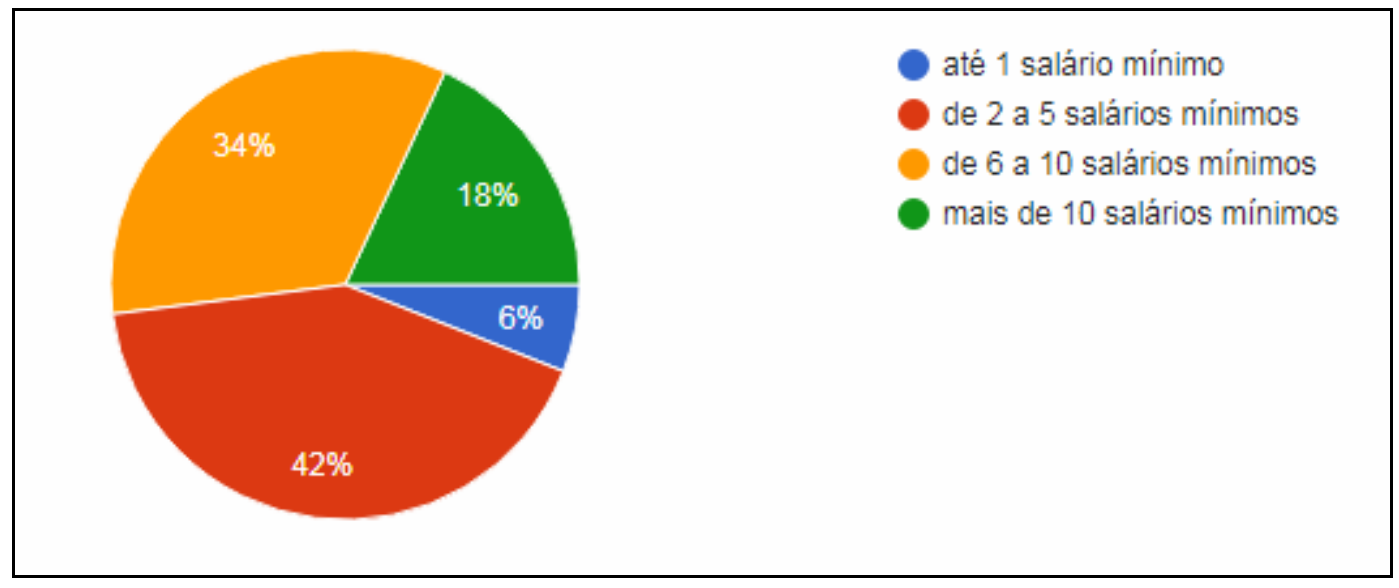

FIGURA 7- Gráfico indicando a frequência, de acordo com a renda média domiciliar, de 50 indivíduos envolvidos no resgaste de animais abandonados ou submetidos a maus tratos, que participaram de estudo desenvolvido nos anos 2017 e 2018, por meio de questionários.

Em relação aos gastos com os animais resgatados, mais de uma alternativa poderia ser considerada, obtendo-se como resultado, que a consulta em clínica veterinária, exames e tratamentos (quando necessários) foi considerada por $47(94 \%)$ pessoas que resgatam animais, como a parte mais onerosa do processo, sendo esta considerada significativamente maior quando comparada aos outros gastos $(p=0,0001)$. Estes são seguidos pelos procedimentos profiláticos, como gastos com vermífugos, vacinas e castração, já os custos com a manutenção do animal (como materiais de higiene e limpeza, diárias de hospedagem) até sua adoção é outro fator importante, sendo a alimentação, o elemento que gera menos despesa às pessoas que oferecem lar temporário (Tabela 2). 
TABELA 2- Frequência e porcentagem dos fatores onerosos relacionados ao resgate de animais até o momento da adoção, citadas por 50 indivíduos envolvidos com resgate de animais em situação de rua e por maus tratos, em estudo realizados nos anos de 2017 e 2018.

\begin{tabular}{lc}
\hline \multicolumn{1}{c}{ Opção } & Frequência (\%) \\
\hline 1.Consulta médico veterinária, exames, & $47(94 \%)$ \\
2.Alimentação & $7(14 \%)$ \\
3.Profilaxia & $19(38 \%)$ \\
4.Custos de manutenção do animal até a adoção & $15(30 \%)$ \\
\hline
\end{tabular}

Os recursos financeiros, nestes casos, provinham da renda própria para 44 (88\%) dos participantes, e/ou de rifas, bazares, sorteios, eventos beneficentes para $16(32 \%)$ pessoas que contribuíram para o estudo; e ainda de doações, anônimas ou não, através de divulgação do caso e pedido de ajuda financeira em redes sociais, como relatado por $23(46 \%)$ das pessoas, e nenhum participante utilizava apoio financeiro do poder público (Tabela 3). Considerando que mais de uma alternativa poderia ser marcada, averiguou-se que houve diferença significativa ( $p=0,0001)$, e que esta foi dada devido ao número significativamente maior de participantes que custeiam com a própria renda, o processo de resgate até adoção do animal.

TABELA 3- Frequência e porcentagem das diferentes origens dos recursos financeiros para manutenção de animais resgatados, citadas por 50 indivíduos envolvidos com resgate de animais em situação de rua e por maus tratos, em estudo realizados nos anos de 2017 e 2018.

\begin{tabular}{lc}
\hline \multicolumn{1}{c}{ Opção } & Frequência (\%) \\
\hline 1 Renda própria & $44(88 \%)$ \\
2.Rifas, bazares, sorteios e eventos beneficentes (similares) & $16(32 \%)$ \\
3.Doações anônimas & $23(46 \%)$ \\
4.Apoio financeiro do poder público & $0(0 \%)$ \\
\hline
\end{tabular}

Em relação ao motivo que levava o entrevistado a se responsabilizar por um animal abandonado ou que foi submetido a maus tratos (Tabela 4), constatou-se que: 48 (96\%) mencionaram o amor aos animais e desejo pessoal de mudar o destino deles; 38 (76\%) ainda eram motivados pela omissão do poder público em relação à causa animal; 21 (42\%) faziam pela responsabilidade social e $13(26 \%)$ participantes foram inspirados por alguém próximo a atuar na causa animal também. Apesar de o participante poder escolher mais de uma alternativa os principais motivos que levam os indivíduos deste estudo a este tipo de ação, foram o amor aos animais e o desejo de mudarem seu destino, e a omissão do poder público em relação à causa animal sendo que entre estes, não houve diferença significativa $(p=0,3318)$. 
TABELA 4- Frequência e porcentagem dos fatores de motivação na responsabilização de um cão/gato, citadas por 50 indivíduos envolvidos com resgate de animais em situação de rua e por maus tratos, em estudo realizado nos anos de 2017 e 2018.

\begin{tabular}{lc}
\hline \multicolumn{1}{c}{ Opção } & Frequência (\%) \\
\hline 1.Omissão do poder público em relação a causa animal & $38(76 \%)$ \\
2. Alguém próximo a inspirou a atuar na causa animal & $13(26 \%)$ \\
$\begin{array}{l}\text { 3.Amor pelos animais e desejo pessoal de mudar o destino } \\
\text { destes }\end{array}$ & $48(96 \%)$ \\
4.Exercer responsabilidade social & $21(42 \%)$ \\
\hline
\end{tabular}

Em relação ao tempo gasto com os animais resgatados por dia (Figura 8), verificou-se que 22 (44\%) participantes têm mais de cinco horas diárias consumidas pela atuação na causa animal, $10(20 \%)$ participantes gastam três horas diárias; outros $10(20 \%)$ despendem duas horas e oito (16\%) participantes utilizam uma horado dia com os animais. A partir desses dados, averiguou-se que houve diferença significativamente maior de participantes que dedicam mais de cinco horas do seu dia, pela causa animal $(p=0,0200)$.

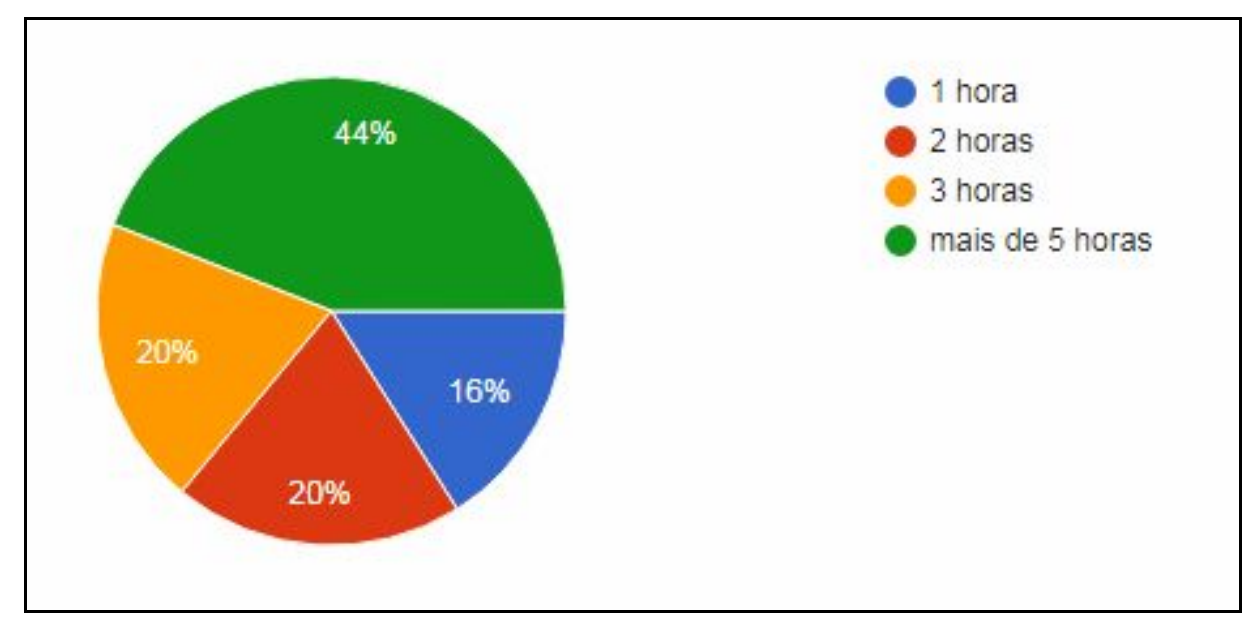

FIGURA 8- Gráfico indicando a frequência, de acordo com a quantidade de horas diárias destinadas a causa animal, de 50 indivíduos envolvidos no resgaste de animais abandonados ou submetidos a maus tratos, que participaram de estudo desenvolvido nos anos 2017 e 2018, por meio de questionários.

Diante das diferentes reações frente à ação de resgate de animais (Tabela 5), seis (12\%) participantes observaram que as pessoas oferecem algum tipo de ajuda como ração, lar temporário e recurso financeiro; 18 (36\%) mencionaram que as pessoas costumam auxiliar na divulgação dos animais destinados à adoção; 44 (88\%) participantes declararam que as pessoas ao encontrarem animais abandonados, normalmente os procuram buscando uma solução, e 11 (22\%) ainda observaram que algumas pessoas se inspiram neles e começam a lutar pela causa animal também. Verificou-se que o número de relatos sobre indivíduos que procuram a causa na tentativa de serem ajudados foi 
significativamente maior do que o daqueles que tentam efetivamente auxiliar a ação $(p=0,0001)$.

TABELA 5- Frequência e porcentagem das diferentes reações de pessoas ao saberem que o indivíduo atua na causa animal, citadas por 50 indivíduos envolvidos com resgate de animais em situação de rua e por maus tratos, em estudo realizados nos anos de 2017 e 2018.

Opção Frequência (\%)

1.Oferece ajuda (ração, lar temporário, recurso financeiro)

$6(12 \%)$

2.Divulga os animais para adoção

$18(36 \%)$

3.Ao encontrarem animais na rua, os procuram atrás de solução

$44(88 \%)$

4.Se inspira e começa a lutar pela causa animal também

$11(22 \%)$

Também foi possível perceber que a maioria das pessoas que vê um animal em situação de rua, ao saber que o indivíduo é protetor independente e atua resgatando animais, entra em contato, para saber se ele pode fazer algo e nem sempre se oferecem a auxiliá-lo. Morais et al. (2014) também verificaram atitude parecida quando descrevem que grande parte das pessoas procuram os protetores na intenção de tirarem alguma dúvida quanto à criação ou destinação de um animal, bem como, há um aumento do número de animais abandonados em sua rua por saberem que os animais poderão ser resgatados.

Mazo e Moura (2017) mencionam em seu artigo, que o IBGE revelou que o número de cães nos lares brasileiros superou o de crianças. Vindo de encontro a estes dados, verificou que a maioria dos protetores independentes não tem filhos e isso permite que direcionem mais tempo e recursos financeiros aos animais.

\section{CONCLUSÃO}

As pessoas envolvidas na causa contra maus tratos animais apresentam perfis diversos, no entanto, alguns pontos parecem ser comuns, a maioria é do sexo feminino, solteiras, residem em casas e utilizam parte da sua renda e tempo em prol da salvação destes animais, e o fazem principalmente por afeto.

Entre as maiores dificuldades está a de encontrar um local para que os animais sejam acolhidos, sendo ajudados por muitos que simpatizam com a causa, mas a grande parte, os procura na tentativa de que eles acolham ou encontrem solução para algum animal necessitado.

É possível notar a necessidade de maior esclarecimento da comunidade em relação à causa animal, na tentativa de se reduzir este tipo de situação, bem como levar ao conhecimento da população o trabalho desses protetores, que são peças fundamentais na luta contra 0 abandono e no resgate e tratamento de animais em situação de maus tratos.

\section{REFERÊNCIAS}

Associação Brasileira de Empresas de Pesquisa (ABEP). Critério de classificação econômica $\quad$ Brasil. 2018.2 Disponível em: $<$ file:///C:/Users/RODRIGO/Downloads/01_cceb_2018.pdf>. Acesso em: 19 junho 2018, 04:23.

BRASIL. Constituição (1998). Artigo 5, XXII e Artigo 170, II. Disponível em: <http://www.planalto.gov.br/ccivil_03/constituicao/ConstituicaoCompilado.Htm>. 
IBGE, Instituto Brasileiro de Geografia e Estatística (2018). PNAD contínua 2017: número de jovens que não estudam nem trabalham ou se qualificam cresce $5,9 \%$ em um ano. Agência IBGE Notícias. Disponível em: $<$ https://agenciadenoticias.ibge.gov.br/agencia-sala-de-imprensa/2013-agencia-denoticias/releases/21253-pnad-continua-2017-numero-de-jovens-que-nao-estudamnem-trabalham-ou-se-qualificam-cresce-5-9-em-um-ano>.

INSTITUTO MAPAA. Segundo OMS Brasil tem 30 milhões de animais vivendo nas ruas. Disponível em <http://www.mapaa.org.br/segundo-oms-brasil-tem-30milhoes-de-animais-vivendo-nas-ruas/>. Acesso em: 13 set. 2018

LEWGOY, B.; SORDI, C.; PINTO, L. Domesticando o Humano para uma Antropologia Moral da Proteção Animal. Revista de Antropologia, v.17, n.2, p.75100, ago./dez, 2015, doi: 10.5007/2175-8034.2015v17n2p75.

MAZON, M.S.; MOURA, W.G. Cachorros e humanos - Mercado de rações pet em perspectiva sociológica. Civitas, Porto Alegre, v. 17, n. 1, p. 138-158, jan.-abr. 2017. Disponível em: <http://www.scielo.br/pdf/civitas/v17n1/1984-7289-civitas-17-01138.pdf>, doi: 10.15448/1984-7289.2017.1.25292.

MOLENTO, C.F.M. et al. Controle Populacional de Cães e Gatos em Dez Vilas Rurais do Paraná, Brasil. Arquivos De Ciências Veterinárias E Zoologia Da Unipar, v.8, n.1, 2005. p.25-31. Disponível em:<http://revistas.unipar.br/index.php/veterinaria/article/view/64/45>. doi: 10.25110/arqvet.v8i1.2005.64.

MORAIS, J. A.; SANTOS, V. P.; POLO, G.; PAPA P.C. Perfil de Protetores Independentes de Cães e Gatos da Grande São Paulo - Resultados Preliminares. Archives of Veterinary Science, v. 19, (supl.) resumo 36, 2014. p. 53-54. Disponível em: < https://revistas.ufpr.br/veterinary/issue/viewlssue/1747/113 >. doi: 10.5380/avs.v24i1.

MOUTINHO, F.F.B.; NASCIMENTO, E. R.; PAIXÃO, R. L. Percepção da sociedade sobre a qualidade de vida e o controle populacional de cães não domiciliados. Ciência Animal Brasileira, Goiânia, v.16, n.4, p.574-588, out./dez, 2015. Disponível em:

<https://www.researchgate.net/profile/Flavio_Moutinho2/publication/284280147_PER CEPCAO_DA_SOCIEDADE_SOBRE_A_QÜALIDADE_DE_VIDA_E_O_CONTR̄OLE

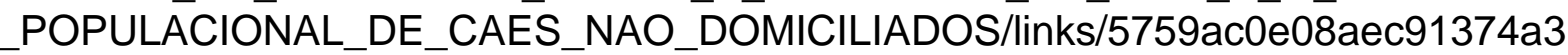
ac72/PERCEPCAO-DA-SOCIEDADE-SOBRE-A-QUALIDADE-DE-VIDA-E-OCONTROLE-POPULACIONAL-DE-CAES-NAO-DOMICILIADOS.pdf>.

DOI: 10.1590/1089-6891v16i430468

NASCIMENTO, F. F. B e PAIXÃO, R. L. Percepção da sociedade sobre a qualidade de vida e o controle populacional de cães não domiciliados. Ciência Animal Brasileira, v. 16, n. 4, p. 574-588, 2015. Disponível em: <http://www.scielo.br/pdf/cab/v16n4/1809-6891-cab-16-04-0574.pdf>. doi: 10.1590/1089-6891v16i430468 
OSORIO, A. Dádiva e antiprofissionalização na proteção a animais de rua. Ambivalências, v.5, n.10, p.105-37, 2017a. Disponível em: <https://seer.ufs.br/index.php/Ambivalencias/article/view/7508>. doi: 10.21665/23183888.v5n10p105-137.

OSORIO, A. Conversões e predisposições à proteção de animais de rua; vocações, sensibilidades e moralidades. Horizontes Antropológicos, v. 23, n. 48, p. 253-274, 2017b. Disponível em: <http://www.scielo.br/pdf/ha/v23n48/0104-7183-ha-23-4800253.pdf>. doi: 10.1590/s0104-71832017000200011.

SANTOS, P. Algumas Questões relativas ao encaminhamento de cães e gatos para adoção. Revista de Antropologia da UFSCAR, v. 7, n. 1, p. 230-247, 2015. Disponível em: <http://www.rau.ufscar.br/wpcontent/uploads/2016/09/12_rau07104.pdf>. Acesso em 20 julho 2018. 